\title{
UM CALEIDOSCÓPIO DE LEITURAS: O STATUS GENÉRICO DE A LA RECHERCHE DU TEMPS PERDU
}

Samira Murad ${ }^{1}$

RESUMO: O artigo sublinha algumas das características que possibilitam a leitura autobiográfica do texto de $A$ la recherche du temps perdu — fato que realmente ocorreu na história da recepção do texto — para mostrar como o flerte de Proust com o gênero autobiográfico está ligado a certos efeitos de leitura propostos pelo texto.

PALAVRAS-CHAVE: autobiografia, $A$ la recherche du temps perdu, leitura.

ABSTRACT: This article aims at highlighting some of the features that allow the autobiographical perception of the book $A$ la recherche du temps perdu — a reading that really materialized in the history of the text's reception in order to show that these genre similarities are related to some reading effects proposed by the text.

KEYWORDS: autobiography, A la recherche du temps perdu, reading process.

\section{Introdução}

O leitor que desejar possuir a Recherche du temps perdu poderá encontrá-la facilmente na seção de ficção em língua estrangeira de qualquer livraria. Numa biblioteca pública, o livro de Proust estará certamente localizado no setor de romances franceses. Mas, a estabilidade que essas classificações conferem ao status genérico do texto de Proust pode mascarar a multiplicidade de leituras que foram sendo realizadas ao longo da história da recepção da Recherche que, para além de sua classificação como romance, já foi pensada como a autobiografia de seu autor, como um gênero híbrido entre o romance e o ensaio (a "terceira forma” de Barthes (1995)) e até, mais recentemente, como uma autoficção . Essa multiplicidade parece estar ligada à ausência de uma marca específica de gênero nas edições da Recherche. A inexistência da palavra "romance" na capa de um livro era bastante comum na época de Proust, como nos explica Gérard Genette: “ a presença da palavra “romance”no início dos textos é uma prática recente e tipicamente francesa [e] nem Balzac, nem Flaubert e nem Zola quiseram utilizar essa indicação"(GENETTE, 1988, p. 64) ${ }^{3}$.

Entretanto, como o próprio Genette avisa “ essa ausência de indicação genérica possibilita a discussão do status genérico da Recherche, ou pelo menos de sua intenção genérica”(GENETTE, 1988, p.

\footnotetext{
${ }^{1}$ Doutoranda em Língua e Literatura Francesa pela Universidade de São Paulo. É membro do Centro de Estudos Proustianos, do Grupo Criação e Crítica e do Laboratório do Manuscrito Literário da Universidade de São Paulo. Publicou, entre outros, os ensaios "Irmãos inimigos? Crítica Genética e Teoria do efeito estético em Le voyage d'hiver de Georges Perec" (Criação em Debate, Humanitas, 2007), “Georges Perec: a anti-Proust?" (Revista de Letras da Unesp, v.48, n. 1, jan/jun.2008), “A peça flaubertiana no Les Choses de Georges Perec” (Eutomia - Revista on-line de literatura e linguística, v. 2, 2008) e “A Teia do conhecimento: modo de usar” (com R. Venegeroles e R. Vicente, Revista USP, v. 80, 2009).

${ }^{2}$ Ver os artigos de Gérard Genette "The Proustian paratexte" e de Marie Miguet-Ollangnier "Sodome et Gomorrhe: une autofiction?” (disponível em http://www.fabula.org/compagnon/proust/miguet.php ).

3 "...the presence of the word novel at the beginning of novels is a recent, typically French practice. Neither Balzac nor Flaubert nor Zola wanted this indication to be used”. Tradução nossa como todas as demais, salvo indicação contrária.
} 
$64)^{4}$, entendida aqui não como a intenção pessoal de seu autor, mas como uma característica textual que permite a existência de determinadas leituras por parte do público. Nesta chave, o objetivo deste artigo é tentar relacionar uma das leituras regulares da Recherche — sua compreensão como autobiografia com alguns efeitos possíveis de seu processo de leitura.

\section{A Recherche como autobiografia: o exemplo da leitura de Du côté de chez Swann por Francis Chevassu}

Em 14 de novembro de 1913, a Editora Grasset lança Du côté de chez Swann, o primeiro volume de $A$ la recherche du temps perdu. Durante o lançamento e nos anúncios que o antecederam (alguns deles encomendados pelo próprio autor como parte de uma campanha de publicidade para o livro) o livro $\mathrm{Du}$ côté de chez $S_{w a n n}$ e a própria Recherche recebem a classificação genérica de romance ${ }^{5}$. Entretanto, já em 7 de dezembro de 1913, Francis Chevassu publica no Le Figaro um artigo sobre Du côté de chez Swann que parece resistir a esses "paratextos não-oficiais", isto é, “comentários [...] que, por várias razões, Proust não pode ou não quis integrar nem ao texto (como, por exemplo, nas páginas "teóricas" do Temps Retrouvé) nem aos paratextos oficiais, como teria sido o caso de um prefácio assinado por ele, por exemplo" (GENETTE, 1988, p. 65) ${ }^{6}$.

Chevassu começa seu artigo explicando aos leitores que o livro que Marcel Proust acaba de lançar é tão original que:

pode, em princípio, desconcertar, pois ele não se classifica, à primeira vista, em nenhum gênero. As licenças que a imaginação do autor nos dá podem levá-lo a ser visto como um romance, mas essas licenças não são romanescas. Além disso, a ausência de intriga e a fantasia da composição mostram que a última preocupação do Sr. Marcel Proust era de realizar aquilo que comumente chamamos de observação da vida. Ao invés disso, podemos pensar que, de uma forma inusitada, o que o escritor queria era redigir uma autobiografia pitoresca e lenta (CHEVASSU, 1913) ${ }^{7}$.

Chevassu propõe a classificação autobiográfica porque recusa a conferência do status romanesco ao livro, como já haviam feito, antes dele, Jacques Madeleine em seu relatório de leitura para a editora Fasquelle e Henri Ghéon em artigo publicado na Nouvelle Revue Française em 1 de janeiro de 1914.

\footnotetext{
4 "Nevertheless, in the case of Proust, the absence of such an indication leaves the question of generic status - or at least of the generic intent of the Recherche - open to discussion".

${ }^{5}$ Ver, por exemplo, o anúncio intitulado "Un roman de Marcel Proust" escrito por René Blum e publicado na revista Gil Blas em 9 de novembro de 1913.

6 "elements of authorial commentary that, for various reasons Proust was unable, or did not wish to integrat either into the text (i. e., the "theoretical" pages of Le Temps Retrouve") or even into the official paratext, as would have been the case of a preface signed by the author, for example".

7 "il risque d'abord de déconcerter, car il ne se classe à première vue dans aucun genre. Les licences que l'imagination de l'auteur semble y donner abondamment le ferait prendre pour un roman; mais ces licences ne sont point romanesques. L'absence d'une intrigue et la fantaisie de la composition démontrent, au surplus, que le dernier souci de M. Marcel Proust fut de s'asservir à ce qu'on appelle communément l'observation de la vie. On songerait plutôt que, sous une forme inattendue, il a voulu rédiger une nonchalante et pittoresque autobiographie”.
} 
Não sendo um romance, a Recherche só pode ser classificada como uma autobiografia. A proposta autobiográfica parece ser, assim, reação a uma experiência de leitura que era bastante diversa daquela a que os leitores estavam acostumados. Essa deriva provocada pela nova experiência de leitura a qual os leitores da Recherche começavam a ser submetidos parece ter estimulado alguns deles a buscarem novas formas de estabilização do texto através da tentativa de precisão genérica. Essa necessidade de determinação do gênero por parte dos leitores ocorre porque, como nos explica Jameson (1975, p. 135), os gêneros:

\begin{abstract}
são essencialmente contratos estabelecidos entre o escritor e seus leitores ou , para usar um termo revivido de maneira proveitosa por Claudio Guillén, os gêneros são instituições literárias que, como qualquer outra instituição social, são baseados em acordos e contratos tácitos. Essa visão dos gêneros está assentada na pressuposição de que toda elocução precisa ser estabilizada por certas indicações e sinais que vão garantir seu uso correto. No dia-a-dia, esses signos são fornecidos pelo contexto da elocução e pela presença física do falante, seus gestos, sua entonação. Quando o discurso não ocorre nessa situação concreta, esses sinais devem ser substituídos por outros tipos de instruções de forma a evitar a deriva da multiplicidade de usos (ou de sentidos, como o último termo era chamado). É a convenção genérica que realiza essa tarefa e garante um substituto interno para as correções e a ajustes possíveis apenas na situação concreta de comunicação ${ }^{8}$.
\end{abstract}

Mas por que Chevassu pode propor essa leitura autobiográfica como forma de estabilizar a "deriva na multiplicidade de usos" que a experiência de leitura da Recherche parecia possibilitar? Quais são as características percebidas no texto que permitem esse tipo de leitura que, fundada por Chevassu, permaneceu por um longo tempo como uma linha importante nos estudos proustianos?

\footnotetext{
8 "genres are essentially contracts between a writer and his readers; or rather, to use the term which Claudio Guillén has so usefully revived, they are literary institutions, which like other institutions of social life are based on tacit agreements or contracts. The thinking behind such a view of genres is based on the presupposition that all speech needs to be marked with certain indications and signals as to how it is properly to be used. In everyday life, of course, these signals are furnished by the context of the utterance and by the physical presence of the speaker, with his gesturality and intonations. When speech is lifted out of this concrete situation, such signals must be replaced by other types of directions, if the text in question is not abandoned to a drifting multiplicity of uses (or meanings, as the latter used to be termed). It is of course the generic convention which is called upon to perform this task, and to provide a built-in substitute for those older corrections and adjustments which are possible only in the immediacy of the face-to-face situation".

${ }^{9}$ Ver, entre outras, a biografia escrita por George D. Painter que está assentada na conviç̧ão de que "o romance proustiano não pode ser compreendido de forma completa sem o conhecimento de sua vida" - "Proust's novel cannot be fully understood without a knowledge of his life"(PAINTER, 1990, p. xix-xx). Por isso o biógrafo propõe como análise "a identificação e reconstrução das fontes, encontradas na vida real de Proust, para todos os seus personagens principais (e para muitos dos personagens secundários), bem como para os principais eventos e lugares descritos no romance" - "identify and reconstruct from ample evidence the sources in Proust's real life for all the major, and many of the minor characters, events and places in his novel" (PAINTER, 1990, p. xx). Ver também a análise que Edmund Wilson (1993, p. 121) faz de A la recherche du temps perdu na qual afirma que "com Proust $[\ldots]$ somos forçados a reconhecer que suas ideias e sua imaginação são afetadas por seus males físicos e psicológicos mais gravemente do que a princípio estaríamos inclinados a supor", o que o leva a tentar um estudo da personalidade do escritor a partir da análise de seus textos.
} 


\section{A Recherche como autobiografia: algumas considerações teóricas}

A primeira característica textual percebida pelos leitores diz respeito ao que o próprio Proust chamou de "tom memorialístico" da Recherche. Em uma carta a Antoine Bibesco, Proust insiste em dizer que a obra que escreve é:

um romance; se a liberdade do tom o aproxima do gênero Memórias, na verdade, uma composição bastante rigorosa (mas de ordem muito complexa para ser percebida logo de início) o diferencia bastante desse gênero. O que há de contingente está lá apenas para exprimir o que é contingente na vida. E, consequentemente, no livro, isso deixa de ser contingente (PROUST, 1984, p. 235) ${ }^{10}$

Ora, esse "tom" destacado por Proust tem a ver com o assunto principal de Du côté de chez Swann tal como percebido por seus primeiros leitores, a saber, as memórias de infância do escritor ${ }^{11}$. Ele tem a ver também com a narração em primeira pessoa que domina a maior parte de Du côté de chez Swann (a exceção, como sabemos, está em “Un amour de Swann”).

Mas as características textuais que possibilitam a leitura autobiográfica não se limitam a isso. Outras ambiguidades no que Lejeune chama de "contrato de leitura" de uma obra permitem (ou, pelo menos, não excluem) esse tipo de leitura.

A primeira dessas características está, como já mencionamos na introdução, na falta de estabelecimento de um pacto autobiográfico ou romanesco claro. A ausência de paratextos que indiquem o caráter autobiográfico do texto bem como a falta do que Lejeune chama de "atestado de ficcionalidade" faz com que não se firme, na leitura do livro, nenhum tipo de pacto, autobiográfico ou romanesco, apesar dos anúncios de lançamento do livro classificarem-no como "romance" e o próprio escritor, em entrevistas e em sua correspondência, insistir nessa categorização. Além disso, como nos explica Genette, contrariamente à prática na época, não há nenhum prefácio precedendo o texto Du côté de chez Swann o que, ainda de acordo com o crítico, indicaria uma estratégia deliberada da parte de Proust que tem por alvo os leitores da Recherche. Voltaremos a isso mais a frente.

\footnotetext{
10 "un roman; si la liberté du ton l'apparente semble-t-il à des Mémoires, en réalité une composition très stricte (mais à ordre trop complexe pour être d'abord perceptible) le différencie au contraire extrêmement des mémoires: Il n'y a dedans du contingent que ce qui est nécessaire pour exprimer la part du contingent dans la vie. Et par conséquent dans le livre, ce n'est plus contingent".

${ }^{11}$ É o que afirma Paul Souday em um artigo escrito em 10 de dezembro de 1913: "Marcel Proust nos dá [...] o primeiro volume de uma obra original: A la recherche du temps perdu, que terá pelo menos três volumes [...] o primeiro já tendo quinhentas e vinte páginas de texto cerrado. Qual é então esse assunto vasto e grave que provocou esse tipo de desenvolvimento? O Sr. Marcel Proust abarca em sua grande obra a história da humanidade ou pelo menos a história de um século? Não. Ele nos conta suas memórias de infância. Sua infância, então, foi repleta de eventos extraordinários? De modo algum — não acontece nada de especial com ele. Passeios, férias, brincadeiras nos Campos Elísios constituem a base da narrativa" - "Marcel Proust nous donne [...] le premier volume d'un ouvrage original: $A$ la recherche du temps perdu, qui comprendra trois volumes au moins [...] le premier comporte déjà cinq cents vingt pages de texte serré. Quel est donc ce vaste et grave sujet qui entraîne des pareils développements? M. Marcel Proust embrasse-t-il dans son grand ouvrage l'histoire de l'humanité ou du moins d'un siècle? Non point. Il nous conte ses souvenirs d'enfance. Son enfance a donc été remplie par une foule d'événements extraordinaires? En aucune façon: il ne lui est rien arrivé de particulier. Des promenades, des vacances, des jeux aux Champs-Elysées constituent le fond du récit (SOUDAY, 1927, p. 7-8).
} 
A outra ambiguidade diz respeito ao que Philippe Lejeune chama de estabelecimento da identidade entre o autor do texto, seu narrador e seu personagem principal (aquele cuja história de vida está sendo contada) - condição necessária para uma leitura claramente autobiográfica da obra. Ora, como o próprio Lejeune aponta, o caso da Recherche é de ambiguidade total, pois além de não haver nenhum "atestado de ficcionalidade" - uma vez que "o pacto romanesco não está claramente indicado no início do livro" (LEJEUNE, 1975, p. 29) — e nenhuma marca de pertencimento ao gênero autobiográfico, o texto não se preocupa em estabelecer nem a identidade nem a não-identidade entre autor, narrador e personagem principal, uma vez que na maior parte do texto, com uma única exceção, ela também bastante ambígua, “o personagem-narrador não tem nome”(LEJEUNE, 1975, p. 29). Ainda de acordo com Lejeune, isso permite à nós leitores escolhermos uma leitura romanesca ou autobiográfica, de acordo com nosso humor, mas "sem dissimular para nós mesmos que somos nós que escolhemos"(LEJEUNE, 1975, p. 31) ${ }^{12}$.

\section{A questão genérica e o processo de leitura da Recherche du temps perdu}

Se, como vimos, algumas características da Recherche criam uma ambiguidade total no que diz respeito a seu contrato de leitura (o que possibilitou a leitura autobiográfica por parte de muitos de seus leitores), parece legítimo questionar a razão da existência dessas ambiguidades, ainda mais quando sabemos que o escritor insistiu, em entrevistas e em sua correspondência, na composição de seu texto - característica que via como parte fundamental do trabalho ficcional — e na decepção de ver "seus leitores imaginando que escrevia a história de sua vida apoiando-se em associações de ideias fortuitas e arbitrárias" (PROUST, 1932, p. 69) ${ }^{13}$. Afinal, nas palavras de Anne Henry, a finalidade ou intenção autobiográfica é um "erro contra o qual o escritor fez protestos veementes, exasperado de ter sido tão mal compreendido por um público desvirtuado por mais de um século de literatura realista e esperando do romancista uma história que se aproxima do testemunho (HENRY, 1983, p. 23-24) ${ }^{14}$.

Ora, se a intenção genérica da Recherche não é a autobiografia, se Proust insiste na questão da composição e recusa a leitura autobiográfica proposta por alguns críticos por que ele não estabelece o pacto romanesco de forma clara? Por que insiste em não nomear seu personagem principal, não estabelecendo nem a identidade nem a não-identidade entre autor, narrador e personagem principal? Por que insiste em estabelecer um pacto de leitura cuja característica principal é a mais total e completa ambiguidade?

Como dito, Genette relaciona a manutenção dessas ambiguidades ao processo de leitura. Explicando que a ausência de prefácio para a Recherche parece estar em contradição com as entrevistas

\footnotetext{
12 “... mais sans nous dissimuler que c'est nous qui choisissons”.

13 “Je vois des lecteurs s'imaginer que j'écris, en me fiant à d'arbitraires et fortuites association d'idées, l'histoire de ma vie" (PROUST, 1932, p. 69).

14 “(une) erreur contre laquelle l'écrivain a élevé de véhémentes protestations, excédé d'avoir été si mal compris d'un public déformé par plus d'un siècle de littérature réaliste, attendant du romancier une histoire que se rapproche du témoignage vécu".
} 
concedidas na época do lançamento de Du côté de chez Swann e até mesmo com parte de sua correspondência com críticos e editores, o crítico explica que:

o leitor ideal, como Rivière, será capaz de sentir aquilo que não é dito. Na ausência desse leitor, os outros serão ajudados, mas apenas indiretamente, uma vez que eles também deverão compreender sem serem instruídos a isso, ou o jogo não terá sentido. Os paratextos e seus níveis sutis de responsabilidade são os meios para esse fim (GENETTE, 1988, p. 66) ${ }^{15}$

Assim, as características ambíguas da Recherche estão ligadas a certos "efeitos" do processo de leitura. Mas que tipo de leitura essas características possibilitariam? Quais seriam os efeitos esperados dessas ambiguidades no contrato de leitura da Recherche?

O primeiro desses efeitos parece ser a identificação. Graças à narração em primeira pessoal, “ o leitor, por meio do processo usual associado com o ato de leitura, identifica-se com o "eu" do narrador e na maior parte do tempo acompanha o ponto de vista limitado do herói que domina o texto" (IFRI, 1999, p. 42) ${ }^{16}$. Em segundo lugar, temos o que Ifri chama de "assimilação dos episódios de vida do narrador à vida do leitor" e que parece decorrer do processo de identificação pois "se o leitor é tão afetado emocionalmente pelo relato dos episódios da vida do narrador, é porque ele não pode evitar de assimilá-los aos eventos de sua própria vida” (IFRI, 1999, p. 41) ${ }^{17}$. Essa “assimilação” é definida por Ifri como a lembrança, por associação de ideias, de episódios semelhantes da vida do leitor. É digno de nota que essas duas estratégias já haviam sido utilizadas por Proust em seu texto "Sur la lecture" e parecem configuram parte importante do que entende pelo processo de leitura ${ }^{18}$.

Por isso mesmo, como sublinha Ifri, "esses processos que visam a implicação emocional do leitor na narrativa não são exclusivos da Recherche, podendo ser encontrados na maioria dos romances" (IFRI, 1999, p. 42) ${ }^{19}$ e, portanto, não explicam, em si mesmos, os motivos das ambiguidades que percebemos na Recherche. Ainda assim, eles justificam, pelo menos em parte, o flerte de Proust com algumas

\footnotetext{
15 "The ideal reader, like Rivière, would be capable of sensing that which he is not told. In the absence of such a reader, the others will be helped, but only indirectly, since they too, are supposed to understand without being told, or the game will no longer make sense. The paratext and its subtle degrees of responsibility are a means to this end".

16 "the reader, through the usual process associated with the act of reading, identifies himself with the "I" and most of the time shares the hero's limited point of view which dominates the text".

17 "if the reader can be so emotionally affected by the account of episodes of the narrator's life, it is because (...) he cannot help assimilating them to events connected with his own life".

${ }^{18}$ Ver, por exemplo, a passagem entre a primeira (narrativa) e a segunda parte (argumentativa) do "Sur la lecture" na qual Proust explica que "antes de mostrar no começo dos Trésors des Rois, porque a leitura, a meu ver, não deve desempenhar na vida o papel preponderante que lhe atribui Ruskin nesse pequeno trabalho, eu devia excluir as encantadoras leituras de infância cuja lembrança deve restar para cada um de nós uma benção. Sem dúvida não fiz mais do que provar pelo tamanho e pelo caráter do desenvolvimento precedente o que eu já havia dito antes: o que as leituras de infância deixam em nós é a imagem dos lugares e dos dias em que as fizemos. Não escapei ao seu sortilégio: querendo falar delas, falei de outras coisas diferentes de livros, porque não é deles que elas me falaram. Mas talvez as lembranças que elas me trouxeram tenham elas mesmas sido despertadas nos leitores, conduzindo-os pouco a pouco — retardando-se nesses caminhos floridos e enviesados - a recriar em seu próprio espírito o ato psicológico original chamado Leitura, com força suficiente para poder seguir agora como que dentro dele mesmo as reflexões que me restam a apresentar" (PROUST, 2003, p. 24-25).

19 “...those processes which aim at emotionally implicating the reader in the narrative are not peculiar to the Recherche - indeed, they can be found in most novels...” (IFRI, 1999, p. 42).
} 
características do gênero autobiográfico como o tom memorialístico e a narração autodiegética (em primeira pessoa, com identificação entre narrador e personagem), uma vez que essas duas características parecem maximizar efeitos dos processos de identificação e assimilação em questão.

Portanto, as respostas para as ambiguidades destacadas tem de ser buscadas, a meu ver, na discussão do projeto estético do escritor . De todo o conjunto que forma a estética de Proust, destaco o que Fraisse chama de "enigma da vida explicado pela arte". Trata-se da função da arte tal como percebida pelo escritor. De acordo com Fraisse (1995, p. 52), Proust "faz parte da família de artistas que acredita que a arte é assunto sério, isto é, ela é um meio privilegiado de encontrar respostas para a interrogação metafísica sobre a significação da vida que persegue todo ser humano" ${ }^{20}$. Essas respostas podem ser encontradas no que Proust chama de estudo de "leis" que regem a vida, palavra que, de acordo com Fraisse (1995, p. 53), "ocorre com esse sentido mais de cento e cinquenta vezes na Recherche"11.

Ora, esse estudo é tarefa do escritor — definido por Proust como alguém com "uma mente pronta a extrair leis" (FRAISSE, 1995, p. 53) 22 — e da própria arte do romance que tem "por missão fazer o leitor perceber as leis que regem a vida" (FRAISSE, 1995, p. 53) ${ }^{23}$.

$\mathrm{Se}$, a obra de arte e o romance tem por missão a exibição das "leis gerais" que regem a vida, essa missão deve, ela mesma, fazer parte da estética posta em ação pela própria Recherche. Assim, é de se esperar que a própria leitura da Recherche possibilite a descoberta dessas "leis" por parte de seus leitores — esse seria o "efeito supremo" do texto. É aí que entra, em nosso ponto de vista, a questão do contrato de leitura ambíguo proposto pelo escritor. Trata-se de estabelecer, numa mesma obra, o que Lejeune chama de "espaço autobiográfico", forma indireta de pacto autobiográfico no qual o leitor "é convidado a ler romances [...] como fantasmas reveladores de um indivíduo" (LEJEUNE, 1975, p. 42) ${ }^{24}$, o que, no caso de Proust, funciona não como a leitura de uma vida em si mesma, mas como um exemplo das "leis gerais" que regem a natureza humana. Esse movimento de leitura que o texto permitiria afasta a concepção de Proust sobre o romance "da hipótese básica [...] de que a ficção é o oposto da realidade" (ISER, 1984, p. 53) ${ }^{25}$ e a aproxima da ideia que " a ficção é um meio de dizer algo sobre a realidade" (ISER, 1984, p. 53) ${ }^{26}$. Afinal, como coloca Proust (1989, p. 474) "27 "a verdadeira vida, a vida enfim descoberta e tornada clara, a única vida, por conseguinte plenamente vivida, é a literatura".

\footnotetext{
20 “ rejoint la famille de créateurs qui pensent que l'art est une affaire sérieuse, c'est-à-dire un moyen privilégié de répondre à l'interrogation métaphysique sur la signification de la vie qui hante tout être humain”.

21 "revient en ce sens cent cinquante-trois fois dans la Recherche".

22 "un esprit prompt à dégager des lois".

23 "pour mission de nous faire apercevoir les lois qui régissent la vie”.

24 "est ainsi invité à lire les romans [...] comme des fantasmes révélateurs d'un individu".

25 "...the basic and misleading assumption is that fiction is an antonym of reality".

26 "...fiction is a means of telling us something about reality".

27 "la vraie vie, la vie enfin découverte et éclaircie, la seule vie par conséquent pleinement vécue, c’est la littérature".
} 


\section{Referências bibliográficas}

BARTHES, R. “Longtemps, je me suis couché de bonne heure”. In: CEuvres complètes. Paris: Seuil, 1995, vol. III, p. 827-836.

CHEVASSU, F. "La vie littéraire”, Paris, Le Figaro, 13 de dezembro de 1913. Disponível em: <http: / / gallica.bnf.fr/ark:/12148/bpt6k2901577.r=.langfr>. Acesso em: 09 set. 2009.

FRAISSE, L. L'esthétique de Marcel Proust. Condé-sur-Noireau: SEDES, 1995.

GENETTE, G. “The Proustian paratext”. SubStance, vol. 27, n. 2, issue 56, 1988, p. 63-77. Disponível em: <http://www.jstor.org/stable/3685140>. Acesso em: 14 set. 2009.

IFRI, P. "Reading and impressions: the example of $A$ la recherche du temps perdu". Modern Language Studies, vol. 29, n. 1, 1999, p. 39-48. Disponível em: <http://www.jstor.org/stable/3195358> Acesso em 06 jan. 2010 .

ISER, W. The act of reading. Baltimore: The Johns Hopkins University Press, 1984.

JAMESON, F. "Magical narratives: romance as genre”. New Literary History, vol. 7, n. 1, 1975, p. 135 163. Disponível em <http://www.jstor.org/stable/468283>. Acesso em: 06 jan. 2010.

LEJEUNE, P. Le pacte autobiographique. Paris: Seuil, 1975.

PAINTER, G. Marcel Proust — a biography. Londres: Penguin Books, 1990.

PROUST, M. Correspondance Générale de Marcel Proust. Paris: Plon, 1932, vol. III. . Correspondance. Paris: Plon, 1984, vol. XI.

A la recherche du temps perdu. Paris: Gallimard, 1989, vol. IV.

Sobre a leitura. Campinas: Pontes, 2003.

SOUDAY, P. Marcel Proust. Paris: Simon Kra, 1927.

WILSON, E. O castelo de Axel — estudo sobre a literatura imaginativa de 1870 a 1930. São Paulo: Cultrix, 1993.

Referência eletrônica: MURAD, Samira. Um caleidoscópio de leituras: o status genérico de A la Recherche du temps perdu, Revista Criação \& Crítica, n. 4, p. 133-140, 2010. Disponível em:

<http://www.fflch.usp.br/dlm/criacaoecritica/dmdocuments/11CC_N4_SMurad.pdf> 